\title{
PAROTITIS COMPLICATED WITH MENINGITIS *
}

\author{
GEORGE N. ACKER, M.D. \\ WASHINGTON, D. C.
}

The appearance of mervous troubles in the course of parotitis did not escape the attention of the older observers. Hamilton in 1758 recorded a case of death in a man of 22 years from meningitis complicating mumps; Astley Cooper the case of an infant who died after an illness of eight days; French in 1812, Malsbrouche in 1867 and Niemeyer have described these conditions without detail. Trousseau relates cases of men 17 and 35 years of age with severe meningitis which disappeared when orchitis supervened.

Gailhard in $187 \%$ compared the meningitis and cerebral complications of mumps to rheumatism of the brain. He reported six cases with stupor, feebleness, slowness of pulse, rigidity of neck, headaches, hyperesthesia, photophobia, delirium and coma. In 1885 Lannois and Lemoine published an important memoir on this subject. They reported a case in which the meningeal complication of mumps was followed by aphasia and right hemiplegia, and was not well for some months. They considered these conditions to be dependent on meningeal lesions of the congestive and inflammatory order accompanied sometimes by lesions of the brain.

Dupre in 1884 proposed the term meningism for these cases, holding there was not a true anatomical alteration of the brain. In some epidemics parotitis appears to lose its benign qualities and causes grave symptoms. Writers have observed meningitis often in cases which have orchitis and are led to believe that such cases are more severe, yet in children, in whom orchitis rarely occurs, meningitis has been noted in a number of cases. The infant has a nervous system easily impressed, which has a tendency to respond to irritating morbid agents by an intense reaction, such as convulsions. This is increased by heredity, neuropathy and alcoholism. Acute meningitis is usually described under three periods: invasion, excitement and depression; each of these periods is marked by a series of symptoms which taken together make a clinical picture, as a rule, constant and characteristic. Such a description cannot be made in the meningitis of mumps. It is true that it may present all the symptoms of acute meningitis, but usually the symptoms take a variable course; nerrous complications are tolerably frequent, due to the

\footnotetext{
* Read at the meeting of the American Pediatric Society, Washington, D. C., May, 1913.
} 
involvement of both the central and the peripheral nerves. A meningeal reaction may present itself in connection with an attack of mumps, coming on two or three days after the swelling of the parotids, although in some cases it supervenes rather later. On the other hand, it has been known to precede the parotid enlargement by some hours.

\section{SYMPTOMS}

The meningitis in question manifests itself by a rise in temperature, headache, insomnia and general discomfort. As a rule, the pulse does not increase in rapidity in proportion to the rise in temperature. In exceptional cases the symptoms are much more severe, there is a sharp rise of temperature, with nausea, vomiting and constipation, there is some rigidity of the neck, Kernig's sign, pupillary changes, strabismus, showing an irregularity of the pulse, disturbance of sensation, and even paralysis of the cranial nerves. These are obviously symptoms of basic meningitis, which is the usual form in this connection. In some instances there are signs of cerebral irritation, delirium, convulsions, spasmodic contraction of the facial muscles, the tongue and limbs, monoplegia and hemiplegia, deviation of the eyes, aphasia, and among spinal symptoms, cutaneous hyperesthesia and pain in the back and limbs. Lesions of the nerves are sometimes consequent to meningitis or occur independently of it. In these cases the virus of mumps seems to attack the sheaths of the peripheral nerves, as well as the walls of the nerve centers.

Many attempts have been made to explain the nervous complication of mumps. Eichhorst attributed them to hyperemia of the brain due to compression of the internal jugular by the enlarged parotid; Jussoud and Groucher by the embolic bodies from the endocarditis due to the parotitis infection; Micilsky to meningitis ; Lannois and Lemoine to a meningoencephalitis or perhaps a thrombosis of the sylvian artery. Comby attributed them more to an hysteria than parotitis; Gallavardin interpreted them as proving a true meningitis due to the poison of parotitis. According to Schottmüller, a post-parotitic meningitis should be regarded as a serous meningitis, with more or less of an accompanying encephalitis.

For a long time the meningeal symptoms which have appeared in mumps had been described, but their pathological character was disputed, and the terms pseudomeningitis parotitis and meningism parotitis employed to designate them. It was not until lumbar puncture was resorted to that a clear idea was obtained of the nature of these meningeal reactions. This showed that it was not a simple functional trouble, but an anatomical modification of the meninges. When in $1902 \mathrm{~A}$. Monad practiced systematically lumbar puncture in the infants attacked by parotitis, and proved six times in eight a lymphocytosis of the cerebrospinal fluid as abundant as that which exists in tuberculous meningitis, 
he demonstrated that this disease is capable of determining an appreciable change in the meninges. The same has been confirmed by Sicard in infants, Chauffard and Boideu in 1904, Dopter, Netter, Comby, Hutinel, Nobècourt and Brelt and Feliciano in 190\%. All found a lymphocytosis in parotitis that had many nervous symptoms. The fluid was clear, with numerous lymphocytes, as in tuberculous meningitis. There was a small amount of albumin, but no fibrin. In the latter disease the meninges are permeable to iodin, but not the first. Dopter states that in simple mumps the cerebrospinal fluid is normal in cellular elements. The lumbar puncture is useful, not only for diagnosis, but also for treatment, as the severe symptoms yield soon after its employment, as has been demonstrated by Chauffard and Widal. The lymphocytosis only lasts for a short time.

\section{BACTERIOLOGY}

That a diplococcus is the pathogenic agent which is the cause of parotitis there can be little doubt from the researches and experiments that have been made. In 1893 Laveran and Catrin described a characteristic diplococcus which they had obtained from the parotid, from the edematous tissue of the face, from joint transudates and from the blood in cases of this disease. In 1896 McCray and Walsh examined the saliva from Steno's duct in ten cases. They found a diplococcus six times. Bein and Michaelis in 1897 and Pick in 1902 reported a similar finding. In 1906 Feissier and Esmein examined the blood in forty-five cases and obtained a diplococcus in thirty-seven. These experiments have been confirmed in this country by Isabella C. Herb of Chicago, who isolated a diplococcus similar to that of the other observers. According to Dopter, the bacteriological examination of the cerebrospinal fluid and meningeal exudate collected after death was sterile.

In the autopsy made by Maximowitch in 1880 the surface of the brain was found edematous and congested with serofibrinous exudate adherent to the pia-mater; the pons and cord were hyperemic.

In 1,705 cases of parotitis observed, there were 158 cases of meningitis, but this does not give the true proportions, as many cases pass unnoticed by careless observers.

\section{DIAGNOSIS}

The quick onset would differentiate this from tuberculous meningitis, as the latter comes on slowly and does not tend to disappear; from cerebrospinal meningitis by the clear fluid and absence of the meningococus. In some cases the parotitis is so slight as not to be noticed, and this adds to the difficulty of the diagnosis.

This meningitis generally disappears rapidly. The motor paralysis can last a long time, but finally gets well. The deafness and optic atro- 
phy appear to persist. This usually harmless disease may develop very alarming symptoms and be followed by permanent damage to important organs, and even end fatally. Among the sequelae of the disease Joffroy mentions peripheral neuritis and paralysis of the extremities lasting for months. The meningitis of mumps, while not a common complication, yet occurs often enough to make one employ careful measures during the first two weeks of the disease.

This is an infectious disease, specific and general in its nature, localizing on the salivary glands, but affecting all of the economy. It is the same as the eruptive fevers, of which it partakes in nature, being contagious and epidemic.

\section{CASE REPORTS}

CASE 1.--R. S., II years old, male, colored, was admitted to the Children's Hospital January 7, 1913, with the following history:

History--Mother in good health; father alcoholic; one infant brother in good health. The boy was in perfect health up to his present illness, having had none of the diseases of childhood. About Christmas, 1912, the mother noticed that the ehild's face was swollen, which condition a physician pronounced mumps, of which there was an epidemic. There was fever, no sore throat, appetite good and bowels open. He had frequent desire to urinate but did so with great diffculty. The urine was of a deep yellow color and moderate in quantity. He could not walk without assistance, and complained of much pain in the legs.

Examination.-When he was admitted to the hospital the sides of the face (parotid region) were swollen and there was great swelling and edema of the serotum (this had come on early in the disease), with marked hypospadia. He took very little notice of surroundings. Lungs, heart and abdominal organs were normal; tongue coated; old ulcer left cornea; child unable to stand; dull and apathetic, but would answer questions in a sluggish manner: pupils unequal in size, the left much larger than the right, but reacted to light; patellar reflexes absent; marked Kernig's sign; no Babinsky.

Course.-Januiry 8. Irritable, complains of pains in arms and cannot turn alone.

January 15. Can roll from side to side in bed, but cannot raise head and shoulders from pillow or sit up. Most of the time is spent in a drowsy state when not actually asleep. Has control of bladder and rectum.

The child up to this time had been on the surgical service, but was transferred to the medical service and came under my charge. A Wassermann made by Dr. W. W. Wilkerson gave a single plus. The first molars were normal.

January 30. Able to sit up.

February 3. Discharge from left ear.

February 16. Examined by Dr. Tom A. Williams. Right patellar reflex feebly present if reinforced; left absent; diadocokinesis not impaired; heel and knee tests negative; ankle-jerk present; can walk and run with eyes elosed without incoordination; sense of deep muscular pain absent in limbs, face and neck. Lumbar puncture was made by Dr. B. M. Randolph and the fluid was found elear with no lymphocytosis. The eyes were examined by Dr. D. K. Shute and pronounced normal.

February 27. Examined again by Dr. Williams. Patellar reflex present in left, slightly. Deep pain sense has been recovered.

March 16. Pupils equal in size; no discharge from ear; reflexes normal; child has gained weight and appears well. 
This case presents the following features common to many of the cases reported: Fever, pains, delirium, marked Kernig sign, patellar reflexes absent, unequal pupils and paralysis. There was a slow pulse on several occasions, but never a decided bradycardia. 'The swelling of the scrotum has been noted several times in adults.

Dr. Williams has made the following comments on the case: The absence of deep reflexes and the loss of the sense of pressure-pain, along with unequal pupils and a positive Wassermann reaction, caused suspicion of tabes dorsalis. Loss of the deep pain conductivity is very commonly a symptom in tabetic radiculitis, but the absence of lymphocytosis rendered the diagnosis most unlikely, especially when the onset of symptoms was so acute as in this case. We know that tabes is merely a sequel of chronic syphilitic leptomeningitis, which invariably shows a lymphocytosis until arrested (see Williams: Am. Jour. Med. Sc., August, 1908). But the case is of great interest as a problem of differential diagnosis, which, in the absence of a cytological examination of the cerebrospinal fluid and the history of mumps, could not have been decided for a long time.

CASE 2.-Boy, 3 years of age, entered the service of Dr. Joseph S. Wall at the Children's Hospital April 23, 1913 with the follewing history:

History.-Father 45 years of age in good health; mother died of tuberculosis nine months previously, 35 years old; otherwise family history good. Birth natural; breast fed for one month only, on account of mother's health. Had always been healtly. Is a well-formed, strong-looking child.

April 14. Complained of pains in the abdomen and had straining of eyes.

April 15. Left side of the neck swollen and the following ray the right side became enlarged. Appeared well until April 20, when he became drowsy.

April 22. About 6 p. m. the eyes became set, followed by a convulsion, clonic and then tonic in character, lasting about thirty minutes. Did not regain conciousness until 6 a. m. the next morning.

April 23. Admitted to hospital. loes not recognize anything; eries out as if in pain; romited milk.

April 24. Right sided convulsions at first, then becoming general, with deviation of the eyes toward the left. Pupils dilated; did not react to light; urine normal; leukocyte count 12,300 .

April 25. Very restless, but takes nourishment well. Examination of the cerebrospinal fluid was made by Dr. B. M. Randolph. The fluid came out under great pressure, clear; white cells 90 per cent.; cells mostly lymphocytes; no bacteria found. Leukocyte count of blood 16,500.

April 26. Muscular twitching of face. Pulse was 60 per minute several times during the day.

April 27. Examined by Dr. Tom A. Williams. Reflexes: Patellar, left present; right exaggerated. Ankle clonus present. Babinsky, right equivocal; left, flexion. Abdominal, left faint; right present. Elbow, left faint; right exaggerated. Deep pain sense present. Motility active. Marked strabismus. Not able to analyze. Pupils dilated; right greater than left; no reaction; tâche cérébrale marked.

April 28. Seemed in stupor the entire night; pulse slow and irregular at times; convulsions during the afternoon involving the entire body. 
April 29. Still in stupor. Restless at times; answered "no" to questions. Lumbar puncture made by Dr. Randolph presented the same characters as the last one.

April 30. Eyes examined by Dr. D. K. Shute and found normal. Not conscious; restless; pupils dilated; gnashing of teeth.

May 1. Restless and noisy; difficulty in breathing at times.

May 2. Death.

Necropsy.-Body of male white child, 3 years old. Section made sixteen hours after death. Brain showed marked venous congestion over vertex. There was an increase of serous fluid in the ventricles. Along the base there was a

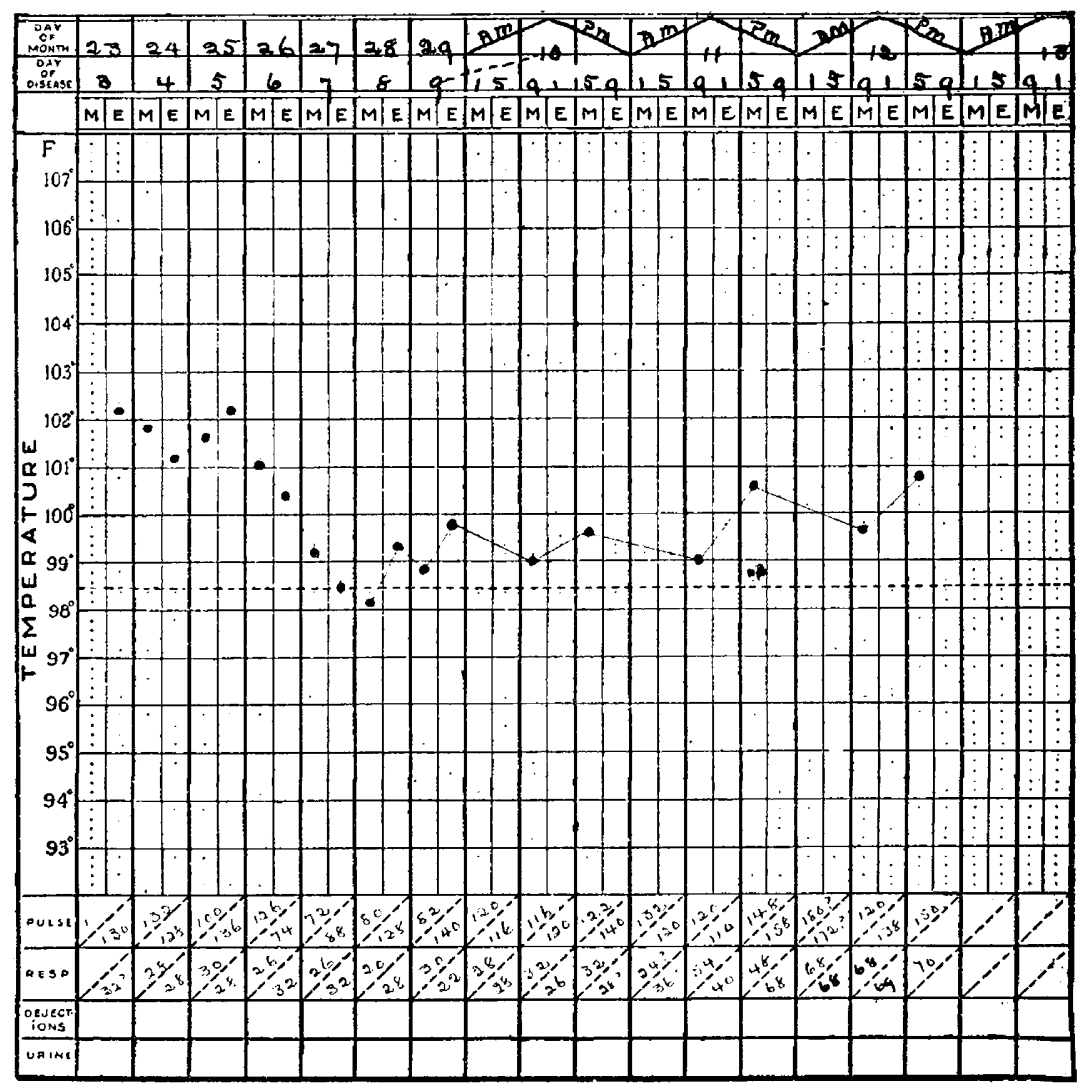

Chart giving data in author's Case 2.

meningitis with a formation of plaques of fibrin. The meningitis did not extend down the cord. On section the brain substance was found normal. Right kidney, stomach and intestines normal, though stomach showed some ptosis. Left kidney, spleen and pancreas showed marked relaxation of their attachments. Pancreas was flaccid and smaller than normal. Pericardium contained small amount of fluid. The lungs were congested and there was a subpleural effusion of blood at base of left lung. There were no areas of consolidation. Bronchial glands normal. No signs of tuberculosis. Mesenteric lymph-nodes enlarged.

Anatomical Diagnosis.-Basilar meningitis. (B. M. Randolph, pathologist.) 
The following cases of meningitis complicating parotitis have been reported in young persons:

HARveY LINDSLY: Two eases of death in brothers occurring a year apart, with similar symptoms. The ages are not given, but one was a student at Princeton College and the other a young medical student in this eity. The fifth day after the onset of mumps there was persistent priapism in both cases, with delirium, restlessness, convulsions and death within two days. Post-mortem examination in the last case showed "Inflammation and congestion of the cerebellum, the cerebrum being normal."

Modro and Healy: Male, 15 years of age, had mumps (temp. 107.2 F.) with recovery. Suddenly became delirious, hyperesthetic, with coma; maniacal outbreak; orchitis; for six months had difficulty in walking; paresis, and incoordination of legs; difficult speech and marked aphasia.

GLENCREAU: Girl 21/2 years old; paralysis right side; convulsive movements at commencement. Recovery in some weeks.

Girl, aged 8 months; light convulsions shortly after the onset of mumps; died within twenty-four hours.

Boy, aged 4 years; extreme restlessness and convulsive movements with the onset of mumps; paralysis of left side.

Boy, aged 5 years. Violent delirium came four days after the onset of mumps. Restlessness with hallucinations. Recovery.

Boy, aged 10 years; severe convulsions with general insensibility; paralysis of left side; marked constipation and difficult micturition. These symptoms lasted a long time.

JoFfroY: Girl, 41/2 years of age. The eighth day of mumps, sharp pains in arms and pruritis and afterwards pains in legs. Tendon reflexes and electrical reactions abolished. Hyperesthesia. There was a slight intermittent albuminuria; flaceid paralysis came on twenty-one days after the onset of the disease in the lower extremities and extended to the upper extremities about ten days afterwards. Bladder and rectum normal.

J. R. Bromwell: Girl, 18 years of age; meningitis; death.

Boy, 11 years of age; four days after the onset of the disease had high fever, delirium, great pain in head, decided intolerance of light, nausea and vomiting. Temperature $104 \mathrm{~F}$., pulse 120 . In seven days the patient was well.

Elsaesser: Three cases. Males from 9 to 11 years of age. Cheyne-Stokes respiration, vomiting, delirium, somnolence, speech disturbance, convulsions, paralysis, death.

ComBr: Boy, 10 years old, presented symptoms of tuberculosis, headache, vomiting, constipation, and rigidity of neck which came on eight days after mumps. Was well in a few days.

Nobècourt ANd Brelet: Girl, 12 years of age. On the third day of mumps there supervened headache, vertigo, vomiting, bradycardia, irregular pulse, pupils contracted, Kernig's sign, stiffness of neck and absence of patellar reflexes. At the acme of the disease lumbar puncture showed an abundant lymphocytosis of the clear cerebrospinal fluid which lasted a few days. After a few days the symptoms disappeared without leaving any trace except that the patellar reflexes were feeble for a long time, but became normal.

NeTter: Boy, 9 years old; violent pains in back, kidneys and limbs; Kernig's sign well marked; temperature $40 \mathrm{C}$. Twenty-four hours later both parotids were swollen. For several days there were brisk movements of the muscles of the face and left arm.

SALAMONSEU: Case 11 years of age. At the end of an attack of mumps there was chorea which lasted for six months and this was preceded by tetany.

J. W. FindLeY: Female, 2 years of age, had mumps fourteen days. On the sixteenth day became paralyzed after convulsions. Left hemiplegia. 
Revellion: Boy, 7 years of age, had mumps with vomiting and fever. In a few days he was apparently well but was weak in left leg. Several weeks afterwards entered hospital; intelligence good; could not stand, rise or hold up head; paralysis of left side of face and eye. Facio-glosso-laryngeal paralysis; all extremities inert; patellar reflexes abolished. In three months recovery with exception of the patellar reflexes.

VAN DUYSE: Girl of 8 years; optic neuritis; violent headache. Later on vomiting and paresis of left side; speech difficult. Sight did not improve.

J. H. Woodward: Eleven-year-old child with neuro-retinitis.

BoYmead: Boy, 111/2 years old. February 6. General malaise and headache. Next day there was nausea, vomiting and epistaxis. Temperature $38.8 \mathrm{C}$, pulse 120. The left parotid became swollen and the following day the right one.

February 10. Could not get up; vomiting; pulse 80; less fever. The next day there was headache, vomiting, constipation, with irregularity of pupils and photophobia. Pulse 58 and irregular.

February 12. Vomiting continued. Pulse 48 and irregular. February 16. Child well.

Hutinel: Girl, 10 years of age. Facial paralysis.

Heubrer: Boy, 13 years of age. Psychosis; loss of memory; orchitis; recovery.

H. ZADE: Boy, 12 years of age. Vomiting, chill, slow pulse. Two days later parotitis. Intense headache and other symptoms of intracranial pressure developed. In ten days there was complete recovery.'

A. STern : Two cases of meningeal complications.

Girl, 8 years old. Diplopia due to paresis of the right internal muscle, showing a lesion of some of the fibers of the inferior branch of the third nerve.

Male, 16 years old. Bradycardia, pulse 30 to 38 per minute, headache, extreme clizziness, slight rigidity of the neck, vomiting, loss of appetite and nystagmus. Hearing poor in right ear.

F. L. Benham: Boy, 15 to 16 years of age. Mumps and orchitis. Temperature $104 \mathrm{~F}$. , pulse 120 , vomiting, frontal headache, delixium, tâche cêrébrale, stupor.

913 Sixteenth Street, N. W.

REFERENCES

Lindsly, Harvey: Va. Med. Gazette, 1851.

Mouro and Healy: Lancet, 1883.

Glencreau: Bull. de thérap., 1884.

Joffroy: Progres méd., 1886.

Bromwell, J. R.: Am. Jour. Obst., 1899, xl.

Elsaesser: Berl. Med. Wehnschr., 1901.

Comby: Soc. de pédiat., November, 1905.

Nobecourt and Brelet: Soc. de pédiat., 1905.

Netter: Bull. Soc. de méd. d. hôp., 1905.

Findley, J. W.: Glasgow Med. Jour, 1906, lxv.

Revelliod: Rev. méd, de la suisse romande, 1906.

Van Duyse: Arch. d'ophth., Paris, 1908.

Woodward: New York Med. Jour., 1907.

Hutinel: Bull. méd., 1910.

Zade, H.: Arch. f. Kinderh., 1912.

Stern, A.: Arch. Pediat., February, 1913.

Dopter, C.: Paris méd., 1910.

Gailhard: 'These de Montpellier, June, 1877.

Cirauffard: Jour. des Practiciens, 1907, xx].

Herb. D. C.: Jour. Am. Med. Assn., 1908, li.

Sacks, B.: Modern Medicine, Osler. 
Gallavardin: Gaz. d. hôp., 1898, lxxi.

Maximowitch: St. Petersburg med. Wchnschr., 1880.

Lannois et Lemoine: Arch. de neurol., 1886.

Monod: Thèse de Paris, 1902.

Laverau et Catrin: Compt. rend. Soc. de biol., 1893.

Teissier and Esmein: Compt. rend. Soc. de biol., 1906.

Teissier and Schoeffer: Congrés méd. Outerne, Paris, 1910.

Benham, F. L.: Lancet, London, 1897, i. 